\title{
Os créditos de carbono no Estado do Amapá, Brasil: uma abordagem preliminar
}

\section{Keila Patrícia Cambraia Santos ${ }^{1}$, José Francisco Carvalho Ferreira ${ }^{2}$ e Eleneide Doff Sotta ${ }^{3}$}

\footnotetext{
1 Mestranda em Desenvolvimento Regional na Universidade Federal do Amapá - UNIFAP, possui graduação em Ciências Ambientais - UNIFAP, Brasil. E-mail: santos.kpc@gmail.com

2 Pós-Doutor em Desenvolvimento Regional pela Universidade Federal do Amapá, Doutor em Geografia e Planeamento Territorial pela Universidade Nova de Lisboa. Membro colaborador do CICS-NOVA. Professor da Universidade Federal do Amapá, Brasil. E-mail: zfcofer@gmail.com

3 Pós-doutorado em Geotecnologias/ Ordenamento territorial e do uso dos recursos naturais - Unité Mixte de Recherche Espace pour le développement, Doutorado em Forestry and Forest Ecology - Universitat Goettingen, Mestrado em Ciências de Florestas Tropicais pelo Instituto Nacional de Pesquisas da Amazônia e Graduação em Engenharia Florestal pela Universidade Federal do Paraná. Atualmente é Pesquisadora da Empresa Brasileira de Pesquisa Agropecuária, Brasil. E-mail: eleneide.sotta@embrapa.br
}

RESUMO: A ação antrópica tem ocasionado mudanças nefastas no clima, que podem ser atenuadas pelo carbono contido nas florestas tropicais, as quais possuem destaque no estado do Amapá, especificamente em sua floresta estadual. Sob o preceito da gestão sustentável, objetivou-se refletir sobre o seu potencial contributo no mercado de carbono, constituindo uma abordagem preliminar. Foi elaborada pesquisa bibliográfica, que inclui o Protocolo de Quioto, as COPs, a quantificação de biomassa no estado e o mercado desses créditos. Pesquisas já realizadas, mostraram que o estoque de carbono total para as árvores é de $182,10+6,02 \mathrm{t} / \mathrm{C}$ ha $^{-1}$ o que teria um importante contributo no mercado regional e nacional, além de propiciar a preservação e a sustentabilidade da região.

Palavras-chave: créditos de carbono; serviços ambientais; Floresta Estadual do Amapá.

\section{Carbon credits in the state of Amapá, Brazil: a preliminar aproach}

\begin{abstract}
Anthropogenic action has caused harmful changes in the climate, which can be mitigated by the carbon contained in the tropical forests, which are highlighted in the state of Amapá, specifically in its state forest. Under the precept of sustainable management, the objective was to reflect on its potential contribution in the carbon market, making a preliminary approach. Bibliographic research was carried out, including the Kyoto Protocol, the POPs, the quantification of biomass in the state and the market of these credits. Research already carried out showed that the total carbon stock for trees is $182.10+6.02 \mathrm{t} / \mathrm{C}$ ha-1, which would have an important contribution in the regional and national markets, as well as providing preservation and sustainability of the region. Keywords: carbon credits; environmental services; Stadual Forest of Amapá.
\end{abstract}

\section{INTRODUÇÃO}

Anualmente, uma grande quantidade de carbono proveniente da queima de combustíveis fósseis e de mudanças do uso da terra é lançada à atmosfera. Como consequência, há o aumento da concentração de gás carbônico, causando o chamado efei- 
to estufa (Soares; Oliveira, 2002). O relatório do IPCC (2007) apresenta evidências de mudanças de clima que podem afetar, significativamente, o planeta até 2100 (ver Miller; Spoolman, 2012). Mesmo que as concentrações de todos os gases de efeito estufa (GEE) e aerossóis se mantivessem constantes nos níveis do ano 2000, seria esperado um aquecimento adicional de cerca de 0,1 으 por década.

As florestas tropicais, em virtude de seu papel na ciclagem de carbono, desempenham uma dupla função: fonte e sumidouro de $\mathrm{CO}_{2}$ (Miller; Spoolman, 2012). Dessa forma, a Floresta Amazônica, que se destaca, globalmente, por ser a maior floresta tropical do mundo, abrangendo $56 \%$ das florestas tropicais da terra, libera entre 1,7 a 2,2 Pg Carbono ano-1 e possui um estoque de carbono de aproximadamente $100 \mathrm{bi}$ Ihões de toneladas, equivalente a cerca de 14 vezes as emissões anuais globais pela utilização de combustíveis fósseis (Manzi, 2008).

A entrada do Protocolo de Kyoto, em 2005, propiciou as bases do mercado de carbono global, constituídos por mercados internacionais e regionais, bem como nos mecanismos de projetos redutores de emissões do tipo Mecanismo de Desenvolvimento Limpo (MDL) ou Implementação Conjunta (IC). É considerado o principal documento referente à redução das emissões dos GEE, que foi oficialmente acordado em 1997 pelos países participantes do Quadro das Nações Unidas para a mudança do clima (Gutierrez, 2009).

No Brasil, o mercado de carbono ainda está limitado ao segmento de oferta de projetos via MDL, possuindo o terceiro lugar em número de atividade de projetos, com 217 projetos (12\%), antecedido pela Índia, 1ㅇ lugar, com 621, e a China em 20 lugar, com 428 projetos (Ribeiro; Resende; Dalmácio, 2008). Contudo, apesar de o Brasil possuir muitas áreas desmatadas, ele é considerado uma matriz energética limpa, além de ser grande detentor de recursos naturais, o que pode torná-lo líder do mercado de carbono do mundo, enquanto que a Índia e China dependem de matérias primas não renováveis.

Além do grande potencial de recursos naturais, o Brasil possui extensas áreas preservadas. Nos seus 27 estados, o Amapá destaca-se por ser o mais protegido na faixa tropical, com 72,52\% de sua área total protegida por unidades de conservação e terras indígenas. Possui uma área de $143,4 \mathrm{mil} \mathrm{km}^{2}$, composta, em sua maioria $(71,86 \%)$, por floresta densa de terra firme, o que o torna um grande detentor de estoque de carbono (Chagas, 2008).

Entre as várias unidades de conservação do estado (Parque Nacional, Reserva Biológica, Estação Ecológica, Floresta Nacional, Reserva de Desenvolvimento Sustentável, Reserva Extrativista e diversas APA), encontra-se a Floresta Estadual do Amapá que abrange uma área total de $23.694,0 \mathrm{~km}^{2}$, correspondendo a $16,59 \%$ de sua área total. Sendo dividida em quatro módulos, contribui aproximadamente com $2 \%$ na conservação das áreas de unidade de conservação da Amazônia Legal. No estado, ela é a segunda maior unidade de conservação (inferior apenas ao PARNA Montanhas do Tumucumaque) e apresenta uma das maiores concentrações florísticas e faunísticas 
do mundo (Euler; Almeida, 2014).

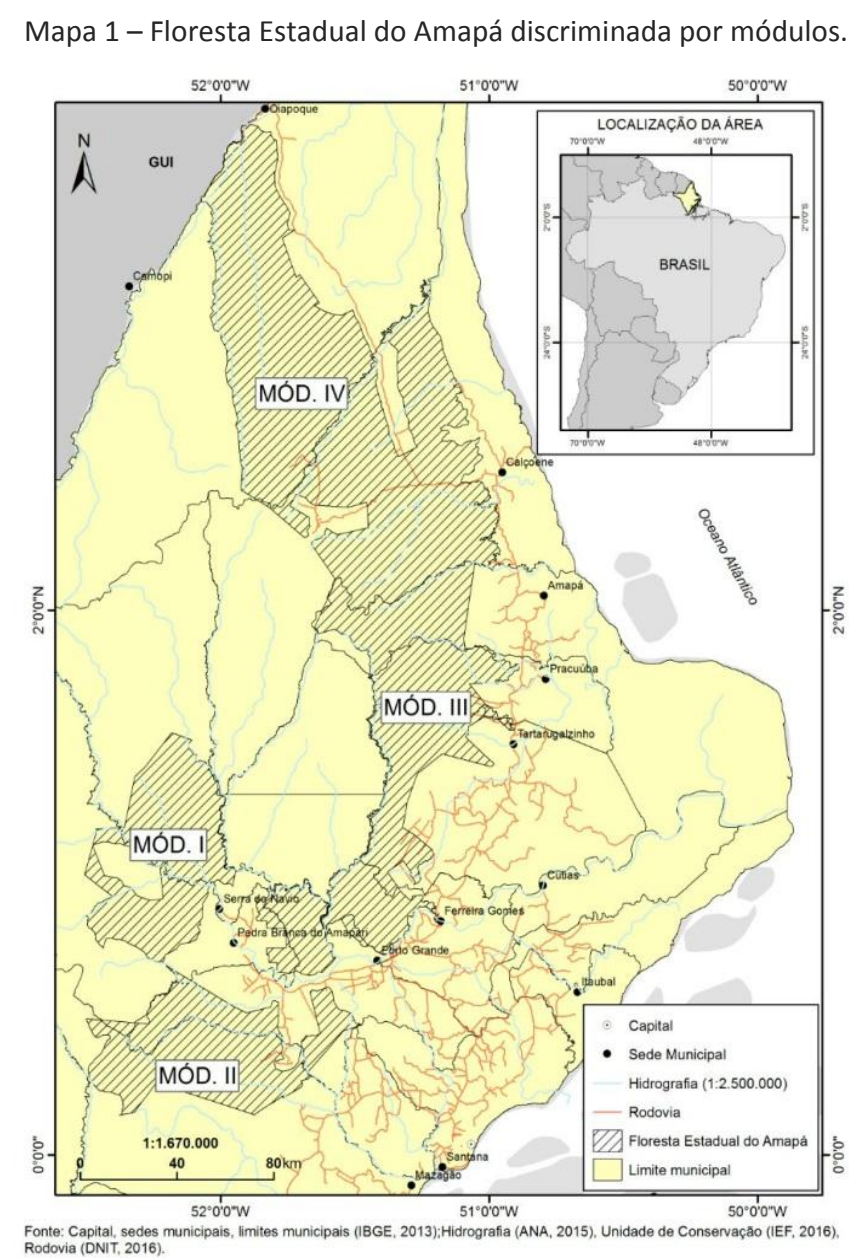

Por seu grande potencial florestal, tem muito a contribuir na geração de biomassa para o estado e para o país, fato esse que necessita ser estudado e avaliado. Dessa forma, objetiva-se fazer uma análise da atual situação do Amapá e seu potencial para o mercado de carbono.

Para alcançar o objetivo proposto, foram realizadas pesquisas bibliográficas e documentais, coleta de dados em materiais na literatura nacional e internacional, concernentes à relação do homem com o clima, às conferências internacionais sobre o meio ambiente e desenvolvimento, ao Protocolo de Kyoto, às COP, à atual situação do estado do Amapá nesse cenário, relacionando com estudos já realizados de quantificação de biomassa na Floresta Estadual do Amapá.

\section{O CLIMA E O SER HUMANO}

O clima de uma região sofre influência direta das atividades humanas, que podem contribuir com alterações diversas sobre o meio ambiente, serem prejudiciais à humanidade e até se tornarem irreversíveis. Entre as atividades capazes de ocasionar 
mudanças meteorológicas de pequenas e médias escalas, a urbanização é a que mais se destaca (Jaureguí; Godinez; Cruz, 1992; Miller; Spoolman, 2012).

Com o crescimento da população, acompanhado pelo crescimento das cidades, faz-se o uso do meio e do solo de forma desordenada e indiscriminada, causando efeitos não só no clima como no modo de vida da sociedade, pois essas alterações modificam a temperatura do ar, umidade, afetando a saúde e podendo agravar doenças cardiorrespiratórias, asma e infecções.

Como parte do processo de alteração no clima, o homem e seu avanço técnico tem expandido suas áreas em busca de ascensão econômica, priorizando o seu desenvolvimento. Com isso, grandes áreas vegetadas, que contribuem para a amenização do efeito estufa, têm sido substituídas por superfícies pavimentadas, que absorvem grande parte do calor térmico durante o dia, emitindo-o durante a noite, ocasionando desconforto térmico e alterando as temperaturas noturnas (Santos et al., 2012).

A vegetação exerce uma influência positiva, tanto no clima quanto na qualidade do ar, pelo fato de as áreas verdes conseguirem reduzir a temperatura dos centros urbanos, pois parte da energia solar disponível para o aquecimento urbano é utilizada no processo de evapotranspiração, além da incidência da radiação solar ser maior em ambientes não arborizados (Costa, 1998). Neste processo, a floresta tropical joga um papel crucial (Miller; Spoolman, 2012).

Sem a influência humana nos fluxos do carbono entre os oceanos, as plantas e o ar, eles seriam praticamente equilibrados. Com a queima de combustíveis fósseis (ação antrópica), são adicionados à atmosfera cerca de 5 bilhões de toneladas de carbono. Dessa quantidade, apenas metade é absorvida pelas plantas e oceanos, sendo que o restante é mantido na atmosfera. No caso das florestas, elas, apesar de serem consideradas um sumidouro de dióxido de carbono, o desflorestamento pode tornála uma fonte emissão (Hinrichs; Kleinbach, 2008).

\subsection{Principais Conferências Internacionais sobre o Meio Ambiente}

Com a segunda Guerra Mundial e a acentuada industrialização, ocorreu um crescimento econômico em vários países do mundo, com a incessante busca de lucro pelas empresas, não se contabilizando as externalidades negativas que tal exploração indiscriminada poderia causar. Posteriormente, depois de um descontentamento social e ambiental generalizado (por exemplo, o "maio de 68"), a ONU tomou a iniciativa de reunir-se com todas as nações e discutir medidas para sanar esses problemas de ordem ambiental, reuniões essas que aconteceram em dois momentos distintos, em Estocolmo, no ano de 1972, e no Rio de Janeiro, em 1992 (Ferreira, 2012).

A conferência de Estocolmo tratou da atuação humana no ciclo da vida, que estava ocorrendo de forma negativa e afetando o bem estar da população e até a perpetuação da espécie. Essa conferência é marcada por uma visão antropocêntrica e também pelos confrontos entre os países desenvolvidos e subdesenvolvidos, uma vez que 
primeiros queriam conservar os recursos naturais em decorrência do seu exaurimento, enquanto os segundos, que estavam se desenvolvendo, alegavam a necessidade de se desenvolver rapidamente devido aos problemas que estavam enfrentando, relacionados à saúde e à miséria (Passos, 2009; Ferreira, 2012).

Em 1992 ocorreu a segunda mais importante Conferência do Clima, a Conferência das Nações Unidas sobre o Meio Ambiente e Desenvolvimento (CNUMAD), conhecida como Eco 92, sediada no Rio de Janeiro com a presença de 172 países. Ela objetivou definir medidas para a redução da degradação ambiental e preservação do meio ambiente, introduzindo também o conceito de desenvolvimento sustentável (preparado pelo "Relatório Brundtland", em 1987), como uma forma de equilibrar os recursos existentes para fornecer para as próximas gerações (Silva Júnior, 2012).

A Eco 92 teve como principais resultados a assinatura de cinco importantes documentos: Declaração do Rio sobre meio ambiente e desenvolvimento, Agenda 21, Princípios para a Administração Sustentável das Florestas, Convenção da Biodiversidade e Convenção Sobre Mudança do Clima. Foi, de fato, nesse período que a comunidade política internacional admitiu que os recursos naturais eram finitos e que era necessário conciliá-los com o desenvolvimento socioeconômico (Ferreira, 2012).

\subsection{Conferência das Partes (COP)}

Da reunião ocorrida no Rio de Janeiro, em 1992, resultou na Criação da Convenção Quadro da ONU, que é debatida ano a ano pelos países signatários, denominados de "Partes". Tendo seu início em Berlim, em 1995, as quatro primeiras reuniões foram realizadas anualmente, mas, a partir da quinta reunião, a COP passou a se reunir de dois em dois anos e é considerada o mais alto órgão decisório no âmbito da Convenção sobre Diversidade Biológica.

Entre os principais objetivos das COP, contam-se mobilizar os governos nacionais, autarquias e organizações da sociedade civil para tomarem medidas efetivas para o combate ao aquecimento global, estabelecer regras e diretrizes internacionais para as políticas nacionais, servir de fórum, onde possam ser debatidas novas propostas, acordos e repassar à ONU a situação das metas prioritárias (Araújo; Carvalho, 2012).

Das diversas COP, até à COP 15, não houve significativo êxito. Os autores supracitados discutem que o ponto central de todas as conferências é o Protocolo de Kyoto (1997), que foi elaborado como instrumento para alcançar os objetivos tanto da COP 1, em Berlim, quanto na COP 2, em Genebra, e os grandes debates sobre os mecanismos de combate ao aquecimento global - MDL, créditos e sumidouros de carbono desde a COP3 até à COP10, embora somente em 2005 tivesse entrado em vigor.

\subsection{Protocolo de Kyoto e o Mecanismo de Desenvolvimento Limpo (MDL)}

Em atitude complementar à Conferência Quadro das Nações Unidas, foi criado o 
Protocolo de Kyoto, visando reduzir emissões provenientes principalmente dos países desenvolvidos, pelo seu histórico na industrialização. Esses países, que faziam parte do Anexo 1, comprometeram-se a reduzir, no mínimo, 5\% de suas emissões de GEE tomando por base os níveis de 1990. Já para os países do Não Anexo 1, do qual o Brasil faz parte, foram tomadas medidas para limitar suas emissões através de tecnologias mais avançadas (Silva Júnior, 2012).

Os países do Não Anexo 1, ou seja, aqueles em desenvolvimento, não estavam inclusos no compromisso quantificado de redução de GEE, devido ao princípio da responsabilidade comum, porém diferenciada. Comum, porque o meio ambiente é um bem de todos, então um efeito causado em um país desenvolvido repercute em outros países bem mais distantes, já que os efeitos não levam em consideração os limites geográficos. Diferenciada, porque a poluição dos primeiros se iniciou desde a Revolução Industrial, enquanto que os segundos só passaram a contribuir com essa poluição décadas depois.

Neste contexto, os países mais industrializados continuavam emitindo diariamente grandes quantidades de GEE, despontando suas indústrias e seu avanço econômico, com pouco compromisso ambiental, enquanto os demais ainda estavam à mercê desse desenvolvimento econômico, além de serem os mais atingidos pelas mudanças climáticas por não terem recursos para enfrentar os seus efeitos.

Entre os 28 artigos do Protocolo, cabe ressaltar os três que tratam dos chamados Mecanismos do Protocolo de Kyoto. Esses mecanismos têm como objetivo auxiliar os países do Anexo I em seus compromissos de redução de GEE, através da geração de créditos provenientes da baixas emissões em outros países e a custos menores em relação às atividades internas, gerando o mercado de carbono. Trata-se de Implementação Conjunta - Jl (Joint Implementation), Comércio de Emissões - ET (Emissions Trading) e o Mecanismo de Desenvolvimento Limpo - MDL (Clean Development Mechanism) (Tolmasquim, 2004).

De acordo com Tolmasquim (2004), a Implementação Conjunta e o Comércio de Emissões são restritos aos países do Anexo 1, englobando a aquisição e/ou transferência de unidades de redução de emissões resultantes de projetos encarregados de fazer essa redução em vários setores da economia. A principal diferença entre os dois está em que o primeiro estabelece o seu projeto em outro país, e o segundo faz as negociações financeiras das unidades de redução de $\mathrm{CO}_{2}$, sem precisar envolver projetos.

O Mecanismo de Desenvolvimento Limpo foi definido no artigo 12 do Protocolo de Kyoto e também é uma forma de fazer com que os países do Anexo 1 reduzam suas emissões, porém difere dos demais pois permite a participação do países do Não Anexo 1, que não estão inseridos no compromisso da redução de emissões. Permite, igualmente, que os países desenvolvidos possam alcançar suas metas de redução de emissões e objetiva, também, o desenvolvimento sustentável.

Apesar de ser um benefício para os países desenvolvidos, não se pode omitir a fal- 
ta de ética presente nesta ação, tendo em vista que, por terem créditos para comprar, os países do Anexo 1 (desenvolvidos) continuarão emitindo, pois pagam a alguém para poluir em menor quantidade, o que é menos dispendioso do que reduzir a sua emissão. Daí vem o interesse das florestas, em particular, das tropicais. Neste contexto, Becker (2004) chama a atenção para a possibilidade de ocorrer o risco de privatização e internacionalização do território nacional, no caso do Brasil, pelo controle das florestas e de transformar o ar em uma mercadoria fictícia, cujo destino seja dirigido pelos mecanismos de mercado.

A geração de créditos de carbono precisa ser comprovada metodicamente por exigência da ONU, por meio de técnicas e métodos por ela reconhecidas, para o MDL ser concebido dentro de padrões e critérios. Para tanto, é utilizado, em um primeiro momento, o projeto de créditos de carbono que aborda todas as informações a respeito do MDL do qual se pretende adquirir as certificações. Para que o projeto possa ser aprovado, ele precisa atender a dois critérios principais: adicionalidade e desenvolvimento sustentável (Barbosa et al, 2011).

De acordo com o World Bank (2007) "o mercado de carbono registrou US\$ 64 biIhões em 2007, dobrando de valor em relação a 2006. Observa-se a posição de dominância do mercado europeu (78\%) e a participação expressiva do MDL, situando-se em $20 \%$ nos dois anos. No tocante ao carbono gerado através de projetos (MDL, IC e outros), esse mercado comercializou 874 milhões de toneladas métricas de carbono (MtCO2e), em 2007, registrando um crescimento de 43\%, em relação ao ano anterior (611 MtCO2e). Em termos de valor, verifica-se um crescimento aproximado de $109 \% "$.

No Brasil, a maior parte dos projetos é desenvolvida na área de cogeração com biomassa e aterro sanitário, os quais representam $44 \%$ das atividades do projeto. Os escopos que mais reduzirão toneladas de $\mathrm{CO}_{2}$ são os de aterro sanitário e os de redução de $\mathrm{N}_{2} \mathrm{O}$, totalizando 113 milhões de $\mathrm{CO}_{2}$, as quais deverão ser reduzidas no primeiro período de obtenção de créditos, o que representa $59 \%$ do total de redução de emissões das atividades de projetos brasileiros (Ribeiro; Resende; Dalmácio, 2008).

A participação brasileira no mercado de carbono ainda está limitada ao segmento de oferta de projetos via MDL, ocupando o terceiro lugar em número de projetos, embora a cada ano a quantidade de projetos tenha aumentado. Portanto, é importante a identificação dos gargalos nacionais que têm limitado o aproveitamento do país desse sistema.

\section{O AMAPÁ NO CONTEXTO DAS ALTERAÇÕES CLIMÁTICAS E DOS CRÉDITOS DE CARBONO}

Becker (2004), refletindo sobre a Amazônia, a partir da ideia de crescente mercantilização da natureza, faz menção de que novas mercadorias fictícias estão surgindo (ar, água e vida), gerando mercados que buscam ser institucionalizados. É neste con- 
texto que a autora coloca o "mercado do ar", cujo principal instrumento é, como vimos, o Protocolo de Kyoto. Do mesmo modo, coloca que este mercado está relacionado à busca de uma nova matriz energética, que se baseia na captura de carbono pela vegetação, e que é no plantio de florestas que este tem a maior incidência no Brasil (ver Wunder et al, 2009).

Neste contexto, olhando de perto para os estados brasileiros, o Amapá detém uma situação privilegiada, pois é o único que possui $72 \%$ de seu território constituído por áreas protegidas, que devem ser vistas como um componente principal para a sustentabilidade da região e não um empecilho ao desenvolvimento. Contudo, para garantir a sustentabilidade da economia regional, requer-se uma gestão e estratégia adequadas.

O estado possui uma vasta cobertura florestal, que, se conhecida e quantificada, pode alavancar o seu desenvolvimento através de seus recursos naturais, especificamente do carbono estocado na sua extensa floresta. Atualmente, o aproveitamento desses recursos, com bases sustentáveis, é um dos maiores desafios para o governo do estado. Neste contexto, a Flota do Amapá foi criada em 2006 com aproximadamente $23.694 \mathrm{~km}^{2}$. Sendo uma UC de uso sustentável, tem como objetivo promover a utilização dos recursos naturais a partir de princípios orientados à sustentabilidade ambiental, social e econômica (Oliveira; Sotta; Higuchi, 2012).

Diante do cenário mundial de alterações climáticas, existe um enorme potencial do estado do Amapá na mitigação dessas mudanças, por meio da preservação de suas florestas, onde apenas $2 \%$ foram desmatadas. A emergente economia do mercado de carbono representa uma oportunidade do estado ser recompensado por manter suas florestas preservadas. O mecanismo internacional de REDD+ está em negociação há alguns anos, porém, decisões importantes sobre sua operação foram feitas na Conferência das partes da UNFCCC, no final de 2013 (Viana et al, 2014), mas o potencial está já assinalado em Wunder et al (2009), concretamente na Floresta Estadual do Amapá.

Os autores (Viana et al, 2014) ainda complementam que no quadro emergente de REDD+, as estimativas de estoque e fluxo de carbono devem seguir rigorosos critérios de medição, verificação e relato, a partir de um nível de referência da floresta, de modo a garantir que a diminuição das emissões sejam genuínas e adicionais. No Amapá, os moradores da RESEX ou Reserva de Desenvolvimento Sustentável e populações extrativistas podem ser os primeiros a se beneficiar de um mecanismo desse tipo, por serem os guardiões das florestas. Contudo, os benefícios podem ser para todos, uma vez que o estado apresenta indicadores socioeconômicos bastante débeis (Castro, 2012).

No contexto da preservação das florestas, note-se que no Amapá existem 4 projetos (tabela 1), que se revelam de capital importância para a preservação das florestas e para a melhoria da qualidade de vida de seus habitantes, envolvendo duas mil famílias. Estes quatro projetos (PROAÇAI; PROCASTANHA; PROCIPÓ e PROMADEIRA), que 
compõem o Programa de Desenvolvimento da Produção Extrativista do Estado, envolvem $28 \mathrm{mil}$ ha de florestas manejadas com 17.444.000 t de $\mathrm{CO}_{2}$ evitadas. Os dados apontam no sentido de ser de enorme potencial econômico a manutenção das florestas em virtude dos seus serviços ambientais prestados, promovendo emprego e renda, mas também maior coesão social.

\begin{tabular}{l|c|c|c|c|c}
\multicolumn{2}{c}{ Tabela 1: Programa de Desenvolvimento da Produção Extrativista do Estado - Proextrativismo } \\
\hline Plano & $\begin{array}{c}\text { No de } \\
\text { Famílias }\end{array}$ & $\begin{array}{c}\text { Custo } \\
\text { Unitário } \\
(\mathrm{R} \$)\end{array}$ & Total (R\$) & $\begin{array}{c}\text { Florestas } \\
\text { manejadas } \\
\text { (ha) }\end{array}$ & $\begin{array}{c}\text { Redução de } \\
\text { Emissões Evitadas } \\
\mathrm{CO}_{2}(\mathrm{t})\end{array}$ \\
\hline PROAÇAÍ & 1200 & $1.500,00$ & $1.950 .000,00$ & 6000 & 3.738 .000 \\
\hline PROCASTANHA & 500 & $1.500,00$ & $750.000,00$ & 15000 & 9.345 .000 \\
\hline PROCIPÓ & 200 & $1.000,00$ & $200.000,00$ & 2000 & 1.246 .000 \\
\hline PROMADEIRA & 100 & $3.500,00$ & $350.000,00$ & 5000 & 3.115 .000 \\
\hline TOTAL & 2000 & - & $3.250 .000,00$ & 28.000 ha & $17.444 .000 \mathrm{t}$ \\
\hline \multicolumn{7}{|c|}{ Fonte: NAP/SECOM, 2013. }
\end{tabular}

A respeito da Floresta Estadual do Amapá (FLOTA), Oliveira, Sotta e Higuchi (2012) desenvolveram estudos, inventariando as árvores com DAP $\geq 5 \mathrm{~cm}$, para as quais foram registrados o DAP a 1,30 m acima do solo, o diâmetro da copa $(\mathrm{m})$ e o estado da árvore (viva ou morta), em 10 parcelas fixas de 10×10 m, dispostas em espinhas de peixe a uma distância de 50 m uma da outra, em uma área total de aproximadamente 15 hectares. Esse estudo mostrou, em seus resultados, a elevada quantidade de carbono estocado por hectare em cada módulo da FLOTA (Tabela 2; Mapa 1).

\begin{tabular}{lcccc} 
& Tabela 2: Estoque de carbono total para a FLOTA (t/C ha-1) \\
& MódULO I & MódULO II & MódULO III & MódULO IV \\
MÉDIA & $175,37 \pm 16,73$ & $\mathbf{1 8 4 , 5 5} \pm 20,01$ & $180,08 \pm 11,51$ & $177,66 \pm 7,57$ \\
D.PADRÃO & 76,37 & 91,31 & 82,21 & 58,66 \\
\hline
\end{tabular}

Fonte: Oliveira, Sotta \& Higuchi, 2012.

Assim como ocorreu a primeira venda de crédito de carbono na tribo Paiter Suruí, em Cacoal, Rondônia, com a negociação de 120 toneladas de carbono para uma indústria de cosméticos por R\$̦ 1,2 milhão, propiciando o desenvolvimento do local, os resultados acima mostram que a floresta densa de terra firme do Estado do Amapá apresenta um potencial substancial quanto ao estoque de carbono, podendo ser comercializado sob uma gestão sustentável e propiciar no desenvolvimento da região, dentro do que Castro (2012) chama de uma estratégia inovadora de desenvolvimento no campo da ecossocioeconomia, ou de uma estratégia de transição para uma economia verde (Viana et al, 2014).

Em um estado em que diversos interesses estão em jogo, ligados à mineração, madeireiras, agronegócio, interesses nem sempre condizentes com o fato de ser altamente protegido (mais de 70\%), traçar uma estratégia que assente na valorização dos recursos naturais, dos quais destacamos a floresta, olhando para o potencial dos 
créditos de carbono, é estratégico para o Amapá. De resto, esta questão não está somente diretamente relacionada com as potencialidades do mercado dos créditos de carbono, mas tem a ver com o modelo de desenvolvimento que se alvitra para o estado, algures entre a ecossocioeconomia (Castro, 2012), a economia verde (Viana et al, 2014), e o aproveitamento do saber das populações tradicionais, que possuem um secular conhecimento acumulado para lidar com o trópico úmido (Becker, 2004).

Este demanda, com certeza, discussão, envolvendo toda a sociedade (o que não tem existido), opções mais sustentáveis, de acordo com o potencial e a vocação do estado, e aquilo a que Becker (2004) denomina de quarta revolução tecnológica (estabelecimento de cadeias tecno-produtivas com base na biodiversidade, desde as comunidades da floresta aos centros de tecnologia avançada), que a ciência e tecnologia terá de operar em toda a Amazônia.

\section{CONSIDERAÇÕES FINAIS}

Com as constantes alterações no clima, ocasionadas pelo uso indiscriminado do meio ambiente e do solo, através do processo de urbanização, foi necessário a ONU tomar atitudes para que os recursos naturais, que antes eram tidos como infinitos, passassem a ser preservados e deixados também para as futuras gerações. Em consequência disso, reuniu os países em dois momentos distintos para discutir sobre as alterações no mundo de forma ambiental.

Essas Conferências, ocorridas em Estocolmo e no Rio de Janeiro, foram propulsoras para tomar medidas necessárias dos países desenvolvidos diminuírem suas emissões provenientes de GEE. Posteriormente, surgiu as COPs com seus produtos, como o Protocolo de Kyoto, que foi um marco decisivo para a redução das emissões, pois estipulava metas e períodos para serem cumpridos pelos países desenvolvidos.

Com o Protocolo de Kyoto criaram-se mecanismos para a diminuição das emissões, entre os quais se destaca o Mecanismo de Desenvolvimento Limpo que visa contribuir para que os países desenvolvidos consigam atingir sua meta de redução de emissões, podendo adquirir créditos de carbono dos países em desenvolvimento. Esse permitiu que os países do Anexo 1 continuassem emitindo, sendo-Ihes mais favorável a compra do crédito do que a diminuição em sua produção.

Apesar do Brasil possuir fontes de energia limpa, como a eólica, de biocombustíveis e principalmente de biomassa vegetal, ele ainda possui o terceiro lugar em número de projetos, limitando-se ao MDL. Essa limitação pode ser dada por uma ausência de gestão, já que muitas governanças possuem um preconceito estrutural contra a resolução de problemas de longo prazo, pois almejam por resultados imediatos, de curto prazo, o que não ocorre com a implementação desses projetos.

Como fator minimizador das mudanças no clima estão as florestas, que são responsáveis por quantidade significativa de estoque de carbono e que, sob uma gestão sustentável, podem ser comercializadas, como é o caso da Floresta Estadual do Ama- 
pá, que possui uma estimativa de biomassa total (aérea + raízes) de $6.493,3 \mathrm{t} / 100 \mathrm{~m}^{2}$. Para que ocorra sua negociação faz-se necessário a implantação de políticas ambientais que possam executar a exploração desse recurso de formas sustentável e viabilizar não só o desenvolvimento regional, mas, igualmente, o nacional.

O potencial existe, embora demande um esforço maior de se estudarem as florestas do estado, o que vai ao encontro da importância da ciência e tecnologia, para operar uma revolução tecnológica na Amazônia. No caso do Amapá, é preciso pensar o estado a partir daquilo que ele tem de melhor: seus recursos naturais, entre os quais se contam a abundante biodiversidade e as florestas, a água e o sol, mas também a partir de seus habitantes, povos tradicionais (indígenas, caboclos, ribeirinhos, quilombolas), que detêm conhecimentos seculares para a manutenção das florestas do estado.

Percebe-se, por fim, que a reflexão sobre o potencial dos créditos de carbono, não começa nem termina nos mesmos, mas exige ter uma perspectiva de desenvolvimento de médio e longo-prazos, que seja capaz de tirar proveito desse potencial e ajude a melhorar a qualidade de vida dos amapaenses, envolvendo questões prementes para o estado, como seja a de conciliar desenvolvimento, ambiente e sustentabilidade, e, porque não, enveredar por uma economia de baixo carbono, capaz de ser referência nacional.

\section{REFERÊNCIAS}

AGENCIA NACIONAL DE ÁGUAS. HidroWeb. ANA. Disponível em: www.ana.gov.br. Acesso em: out. 2016.

ARAÚJO, Geraldo José Ferraresi de; CARVALHO, César Machado. Os avanços e fracassos da 15a Conferência das partes de Copenhague: um estudo exploratório. Revista Iluminart, Ano IV, no 9, Nov., 145-163, 2012.

BARBOSA, Jeciléia Batista et al. Crédito de Carbono: Orientação para as Ações Estratégicas e de Controle na Gestão do Projeto. VIII Convibra Administração - Congresso Virtual Brasileiro de Administração, p. 1-13, 2011.

BECKER, Bertha Koiffmann. Amazônia Geopolítica na virada do III Milênio. Garamond: Rio de Janeiro, 2004.

CASTRO, Manoel Cabral de. Crescimento Econômico e Desenvolvimento Sustentável. Trabalho em Progresso - Versão Preliminar preparada para o evento Amapá na Rio + 20 Amazônia Preservada. Macapá, 2012.

CHAGAS, Marco Antônio. Tumucumaque: O "Big Park" e a História do Conservacionismo no Amapá. Rio de Janeiro: Edição do autor, Rio de Janeiro - Macapá, 2008.

COSTA, Antônio Carlos Lôla da. Estudo de Variações Termo-Higrométricas de Cidade Equatorial devido ao Processo de Urbanização: O caso de Belém-PA. São Paulo: EESC-USP, 1998.

DEPARTAMENTO NACIONAL DE INFRAESTRUTURA DE TRANSPORTE - DNIF. Disponí- 
vel em www.dnit.gov.br. Acesso em: out. 2016.

EULER, Ana Margarida Castro; ALMEIDA, Marcos Renato Dantas de (Coord.). Plano de manejo da Floresta Estadual do Amapá - Resumo Executivo da FLOTA/AP, Macapá/AP, 2014.

FERREIRA, José Francisco Carvalho. A Sustentabilidade do Alto Douro Vinhateiro: realidade ou utopia? Contributo para a avaliação e melhoria da sustentabilidade da região. 2012. 532 f. Tese (Doutorado em Geografia e Planeamento Regional) - FCSHUNL, Lisboa, 2012.

GUTIERREZ, Maria Bernardete. O Brasil e o mercado de carbono. Regional, urbano e ambiental, no 3, dezembro de 2009, IPEA, 2009.

HINRICHS, Roger A.; KLEINBACH, Merlin; REIS, Lineu Belico dos. Energia e Meio Ambiente. Tradução da 3a edição norte-americana. São Paulo: Cengage Learning, 2008. INSTITUTO BRASILEIRO DE GEOGRAFIA E ESTATÍSTICA - IBGE. Base contínua 1:250.000: versão 2013. Mapoteca Digital, IBGE, 2013. Disponível em: www.ibge.com.br. Acesso em: out. 2016.

INSTITUTO ESTADUAL DE FLORESTAS DO AMAPÁ - IEF. Disponível em: www.ief.ap.gov.br. Acesso em: out. 2016.

INTERGOVERNMENTAL PANEL ON CLIMATE CHANGE - IPCC. Climate Change 2007: The Physical Science Basis, Summary for Policy Makers. Geneva: IPCC, 2007. JAUREGUÍ, E.; GODINEZ, L.; CRUZ, F. Aspects of heatisland development in Guadalajara, Mexico. Atmospheric Environment, v. 26B, n. 3, 391-396, 1992.

MANZI, A. O. Amazônia no contexto das mudanças climáticas globais: aspectos físicos. Anais... Seminário Internacional Amazônia dinâmica do carbono e impactos sócio-econômicos e ambientais, Boa Vista, 2008.

MILLER, G. Tyler; SPOOLMAN, Scott E. Ecologia e Sustentabilidade. Tradução da 6a Edição Norte-Americana. São Paulo: Cengage Learning, 2012.

MOREIRA, Helena Margarido. A formatação da Nova Geopolítica das Mudanças Climáticas. VI Encontro Nacional da ANPPAS, 18 a 21 de Setembro, Belém-PA, p. 1-19, 2012.

OLIVEIRA, Lana Patrícia Santos; SOTTA, Eleneide Doff; HIGUCHI, Niro. Quantificação da biomassa na Floresta estadual do Amapá: alometria estimativas do estoque de carbono. 10 Edição, Instituto Estadual de Florestas do Amapá-IEF. Série Técnica, Macapá: EIF, 2012.

PASSOS, Priscilla Nogueira Calmon de. A conferência de Estocolmo como ponto de partida para a proteção internacional do meio ambiente. Direitos fundamentais \& democracia, vol. 6, n. 5, 1-25, 2009.

RIBEIRO, Maísa de Souza; RESENDE, Amaury José; DALMÁCIO, Flávia Zóboli. Uma Análise Multidimensional dos Projetos Brasileiros de MDL - Mecanismos de Desenvolvimento Limpo. Revista de Contabilidade da UFBA, Salvador-BA, v. 2, n. 1, janeiro/abril 2008, 14-29.

SANTOS, Keila Patrícia Cambraia et al. Índices de tendências climáticas associados à 
"ilha de calor" em Macapá - AP (1968 - 2010). Revista Brasileira de Ciências Ambientais, Número 23, 1-16, 2012.

SILVA JÚNIOR, Jorge Henrique e et al. As Conferências Internacionais sobre Meio Ambiente e a RIO+20. VII Congresso Norte e Nordeste de Pesquisa e inovação, PalmasTO, 2012.

SOARES, Carlos Pedro Boechat; OLIVEIRA, Márcio Leles Romarco de. Equações para estimar a quantidade de carbono na parte aérea de árvores de eucalipto em Viçosa, Minas Gerais. Revista Árvore, Viçosa-MG, v.26, n.5, 533-539, 2002.

TOLMASQUIM, Maurício Tiomno. Alternativas energéticas sustentáveis no Brasil. Rio de Janeiro: Relume Dumará: COPPE, CENERGIA, 2004.

VIANA, Viana et al. Economia verde no Estado do Amapá, Brasil: avanços e perspectivas. London: International Institute for Environment and Development-IIED, 2014.

WORLD BANK. State and trends of the carbon market 2007. Washington, D.C.: World Bank, 2007.

WUNDER, Sven (Coord.) et al. Pagamentos por serviços ambientais: perspectivas para a Amazônia legal. Série Estudos, 10. Brasília: MMA, 2009.

Artigo recebido em 02 de maio de 2017.

Aprovado em 31 de julho de 2017. 